
degrees of cold, under a pressure of from four to six atmos-
pheres. The liquefied carbonic acid is conducted in a tube four meters long; two combined pumps produce barometric vacuum over that acid, which solidifies in consequence of the aforesaid, solidified carbonic acid, passes a tube of smaller diameter, in which a current of oxygen is caused by a genelarge-sized thick-walled shell. Pressure may be brought up cember, under a pressure of 300 atmospheres, a liquid jet of moment when the compressed. and cooled-down gas was passing from its high pressure to atmospheric pressure. To great rush of hot water from the hot-water cock of a bath." great rush of hot water from the hot-water cock of a bath. in vaporizing oxygen the same day as I liquefied it, and a few experiments were made in the laboratory of the Ecole Nor-
male, in the presence of MM. Boussingault, Henri Sainte Claire Deville, Berthelot, Mascart, etc. These eminent men says the Journal des Debats, declared themselves satisfied that the nitrogen was reduced to the condition of little drops while the hydrogen became visible in the form of a vapory

The method employed by M. Cailletet is that of a sudden mospheric pressure. This sudden oxygen to that of at produces a great external work, and is thus the cause of great lowering of temperature. The refrigeration consequent on the slackened pressure may easily reach $-200^{\circ} \mathrm{C}$.
below the initial temperature of the gas. The sudden reduction of 250 atmospheric pressures condenses the gas into a to gas is extremely transitory; for radiating heat almost instantanewords, brings them back to their gaseous form. In my researches, I have aimed at converting oxygen into a relatively permanent liquid to be collected in a receiver, so as to be able to measureits density and maximum tension. On the 11th of January I forwarded from Geneva the following telegram to M. Dumas, Secrétaire Perpétuel d

"I have just liquefied hydrogen with a pressure of 650 atmospheres and 140 degrees of cold. The gas solidified under the effect of evaporation. The jet had a flashing bluish color
somewhat like steel. The gushing jet fell on the ground, nied by a strident hiss. Lumps of hydrogen were kept intact in the tube."

M. Dumas immediately laid my discovery before the Sociét d'Encouragement. From a report of a lecture of his on the

M. Dumas, the illustrious chemist, began by reminding
his hearers, with legitimate pride, that he had foreseen some forty years ago, in his Traite de Chimie, that hydrogen was the gaseous form of a metal. After dealing at some length with the inductions which had led him to that conclusion,
M. Dumas laid some stress on the distinction to we made M. Dumas laid some stress on the distinction to we made
between M. Raoul Pictet's and M. Cailletet's experiments. M. Cailletet has proved the possibility of reducing all gases to the liquid and the solid states. M. Pictet has really $\mathbf{r}$ And now to conclude. I here beg to thank the scientific And now to conclude. There beg to thank the scientific
world for the handsome welcome they have given my dis-
covery. Still, the scientific world is not the world. A supcovery. "Still, the scientific world is not the world. A suppressed titter has rippled on the faces of the ignorant, followed by the query; " What's the use of it?" Well, it is perclams the fault of the scientific world if so groveling an manuals treating of physics, chemistry, and other sciences, lay more stress on tangible results than on the workings of the creative mind. Is it astonishing that man, who is naturally prone to value none but paying facts, should, when
left to the mercies of a practical manual, remain unsympathizing whenever his attention is called to the laws which are at the root of creation? The philosophical temper which reverences God on account of the perfection of His though ought to be the fruit of scientific education. Science is sedulously turning his mind to the divine first pris which rule the world.-Nineteenth Century.

\section{LIQUEFACTION OF GASES.}

IT was reserved for Dr. Andrews to show experimentall that the liquid and gaseous states are perfectly continuous His conclusion that every body, whether liquid or gaseous, has its own crictical point, contained the germ which, in the "permanent gases." It follows from these memorable experiments that if a gas be kept above its critical temperature, no amount of pressure will be able to liquefy it; the most that can be done is to reduce it to a homogeneousbody, which is neither a gas nor a liquid. If while it is in this neutral state the temperature be lowered, it will condense
into a liquid; but if only the pressure be diminished, it will return to the gaseous state.

Here, then, at last we see the two conditions necessary to perature. Dr. Andrews clearly apprehended these two temditions, for we find him subjecting oxygen to pressures exceeding any used by Faraday, while surrounding the gas with one of the most powerful refrigerating agents known, viz., a mixture of solid carbonic acid and sulphuric ether.
Still his endeavors met with no success; oxygen gave no

M. Berthelot, the eminent French chemist, still more re cently, carried the pressure up to 800 atmospheres, but without effecting liquefaction.

It occurred, independently, to M. Louis Cailletet, of Chatillon-sur-Seine, and M. Raoul Pictet, of Geneva, that the incoercible gases might yield to the intense cold that would pressed to a very high degree. According to Poisson's formula, this expansion should lower the temperature of the gas by about 200 degrees Centigrade. Both set to work and in both of which the embodiment of this principle forms salient feature.

It is not to be supposed that M. Cailletet's success is the mere outcome of a fortuitous combination of circumstances There are instances of this happy chance in the history of scientific discovery, but they are few. His success is en
tirely the result of a well-directed and sustained investigatirely the result of a well-directed and sustained investiga-
tion. At different intervals during the last ten years this tion. At different intervals during the last ten years this
subject has engaged his attention. Availing himself of the subject has engaged his attention. Availing himself of the
mechanical power at his iron works at Chatillon, he collected

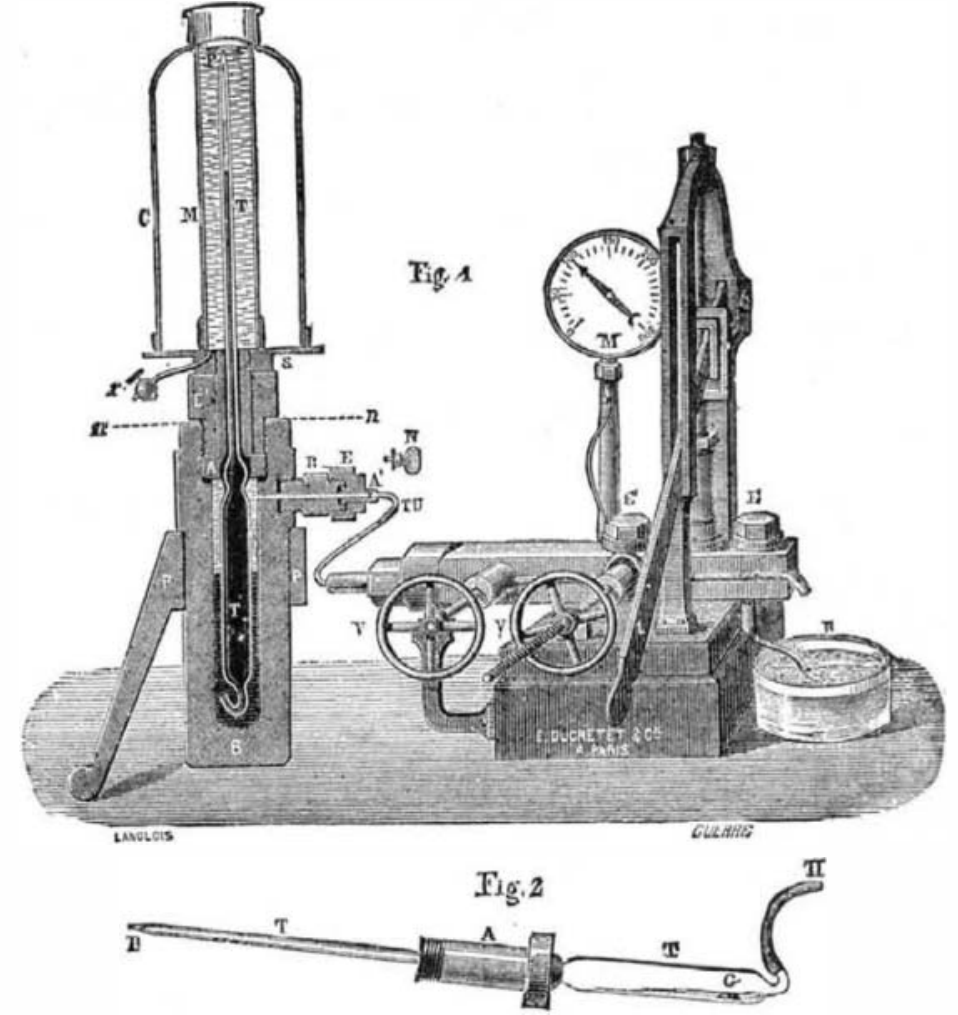

CAILLETET'S APPARATUS FOR THE LIQUEFACTION OF GASES.

a large amount of data, which, in the true spirit of a physifnally solved the problem. This was on the $2 \mathrm{~d}$ of last De-
cember; on the $3 d$, he wrote a short note to $M$. H. SainteClaire Deville, in which he states with pardonableenthusiasm that he had succeeded in liquefying carbonic oxide and
oxygen. As he was at that moment a canditate for a seat in the Mineralogical Section of the Academy of Sciences, and advised $\mathrm{M}$. Sainte-Claire Deville to seal his letter and remit it to M. Dumas, the perpetual secretary of the Academy. Nearly three weeks later, on December 22d, M. Pictet communicated his results to the secretary, and singularly the Academy, viz., that held on December 24th. The pri this does not detract one tittle from the merits of M. Pictet's M. Cailletet's apparatus will be understood from the accompanying illustration, Fig. 1. A tube, T, Fig. 2 , of very fine bore toward its upper extremity, and capable of supporting a pressure of 500 atmospheres, is partly filled with the gas to be liquefied. The lower portion of the tube ex-
pands to form a capacious bulb, which is filled with mercury, and inserted in a reservoir containing mercury and water. to allow pressures of 800 atmospheres to be used with thick fect safety. The water is forced in by a strong pump, and, according as it enters, the mercury rises in the capillary tube, of 200 atmospheres is attained by a few strokes of the pump,
and is recorded by a metallic manometer. By means of a and is recorded by a metallic manometer. By means of a plunger, V, the pressure may be very gradually increased up urrounded by a freezing mixture, or by water at any desired Inerature.

In the case of most gases, the manometer remains stationnomenon, which is at variance with Boyle's law (a law absonomenon, which is at variance with Boyle's law (a law absobegins. When an appreciable quantity of the gas has been liquefied, upon gradually diminishing the pressure the liquid begins to boil and returns to the gaseous condition. But
if the valve $V$ ' be suddenly opened, the gas will as suddenly expand, and, undergoing a very considerable reduction of emperature, a portion of it will be liquefied, filling the upper part of the tube with a sort of cloud or mist. These may be easily exhibited to an audience by projection on a

In the case of the other gases, the liquefaction has not yet proceeded further than its incipient stage. Thus oxy-
gen under a pressure of 270 atmospheres and a temperature of -29 degs. Was still gaseous; but on suddenly opening the valve $V^{\prime}$, the tube was filled with a cloud, which denoted a commencement of liquefaction, if not of actual solidification,
as some have thought. M. Cailletet is now constructing an
ployed for the Woolf's bottles or bent glass tubes are em-

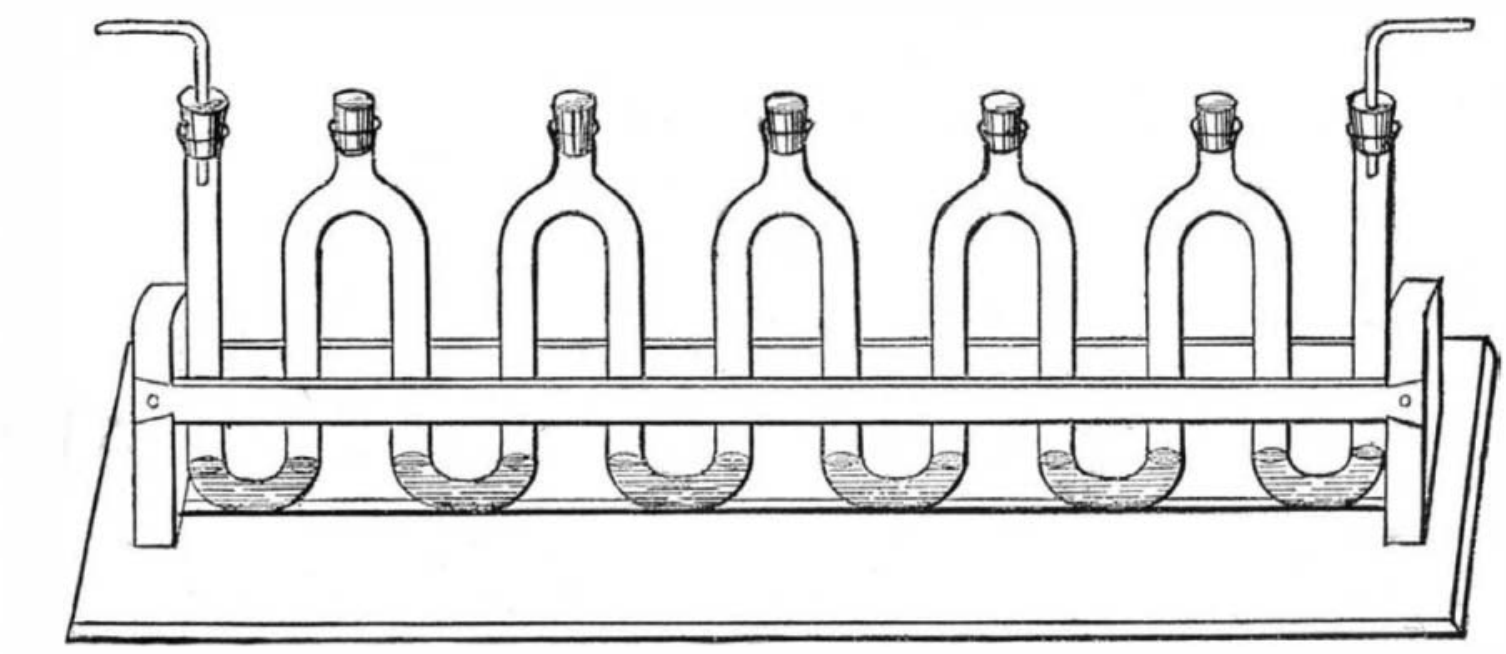

IMPROVED GAS-ABSORBER.

pparatus with which he hopes to clear away this doubt and compression. The gas is not converted into ozone during whe oxygen is not surrounded by a cooling mixture, perature arising from its compression.
I In the experiments which were made in the laboratory of the Ecole Normale, Paris, on December 30, in presence of o a pressure of 200 atmospheres and the temperature of iving way. On opening the valve, tiny drops of an appre-
ingens of ciable volume were visible for about three seconds. Hydrocas, showed itself the most refactory of all the gases; still when compressed to $28 \hat{0}$ atmospheres and suddenly released, ne, extremely tenuous mist. To leave no doubt on the matter and to satisfy the physicists present, the experiment result.

On January 14th, M. Cailletet experimented with atmospheric air. Having removed all traces of moisture and carrounded it with liquid nitrous oxide. When the manometer corded 200 atmospheres, streams of liquid air flowed down the of the tube, its upper surface was frozen; and on the prompt emoval of the refrigerating substance, the meniscus was obrozen or solid air.

M. Pictet has obtained not only the cloudy appearance reminiature showers of hydrogen hail. Both physicists will oubtless continue their experiments until they have comand hydrogen for use in the chemical laboratory. In an early number we shall describe M. Pictet's apparatus and shown in Fig. 1 is the original one used at the experiments made in the Ecole Normale, and has been constructed pecially for physical laboratories. MM. Ducretet \& Co.

A G'AS-ABSORBER.

By G. GORE, LL.D, F.R.S

EVERY chemist is well aware that by the single passage of Dubble or stream of gas through a liquid, the former touches

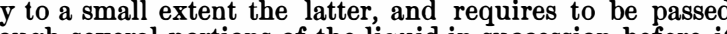
bottles or bent glass tubesiderable 
bulk of liquid must be used, and in both cases a number of $\quad$ NEW 500 H. P. COMPOUND ENGINES. junctions must be made with the different parts of the apparatus, and a proportionate risk of leakage incurred. I have therefore constructed the apparatus shown by the adopted in Yorkshire, but the necessity for economy in fuel bulk of liquid with a gas, or speedily absorbing a small manufacturer's need of uniformity of velocity at which his junctions to gas ay a liquid, without requiring many machinery should be driven has, generally speaking, failed of about half an inch external diameter, bent into a series of built by -Messrs. Pearson \&. Spurr, of Birstall Foundry, four or six double curves, the upper part of each of which is near Leeds, and erected by them at the Queen Street Mills, provided with a neck (closed by an India-rubber bung), so
that each limb of the tube may be readily, cleaned. The tube of Messrs. R. Brearley \& Sons. They are from
new designs by Mr. G. Sellers, and are intended to work up is supported and kept steady in the manner shown in the sketch.

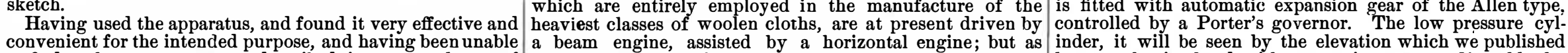
convenient for the intended purpose, and having been unable a beam engine, assisted by a horizontal engine; but as inder, it will be seen by the elevation which we published
to find such an arrangement described in any catalogue of
chemical apparatus, I have ventured to publish this descrip.
these old and of insufficient power to drive the ma- last week, is fitted with expansion gear, adjustable by
chine in the extended mills, Messrs. Brearley decided hand, by. means of the hand screw moving the joint block \begin{tabular}{l|l} 
to find such an arrangement described in any catalogue of \\
chemical apparatus, I have ventured to publish this descrip- \\
tion.-Chemical News.
\end{tabular} new designs by Mr. G. Sellers, and are intended to work up readily adjusted by means of the right and left hand
to from 450 horse power to 500 horse power. The mills,
which are entirely employed in the manufacture of the as is fitted with automatic expansion gear of the Allen type, purpose they have obtained the compound engines about to Both the high and low pressure cylinders are fitted with do valve, and to obtain a space between the chess to either Jod, supported by two extra glands should by a suitable joint be adjustable in order to modify the relative suitable jof covers. The slide valves are of the Meyer type, and are right and left hand (1) and, as nearly as practicable, uniformly, and for this

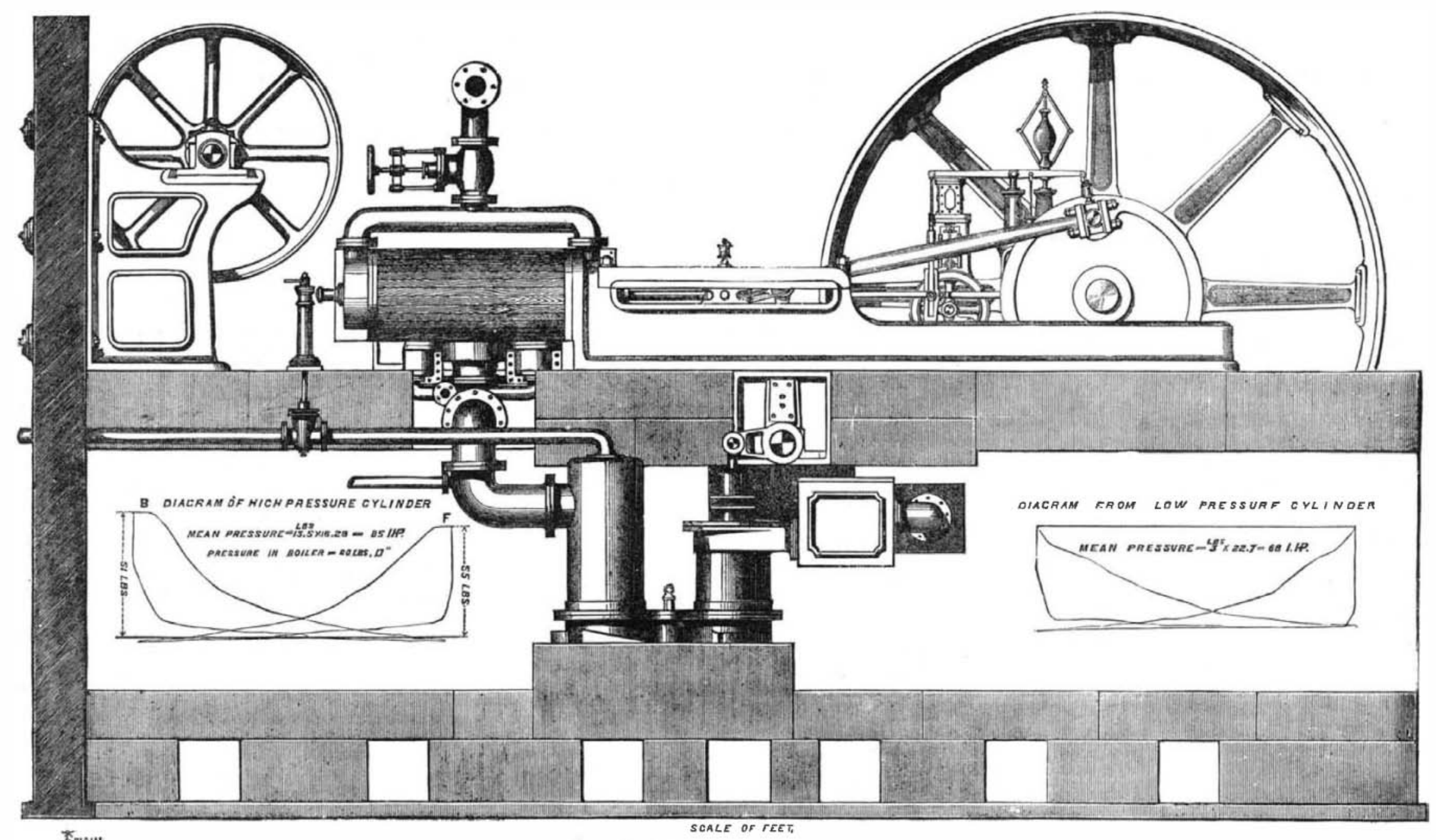

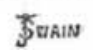

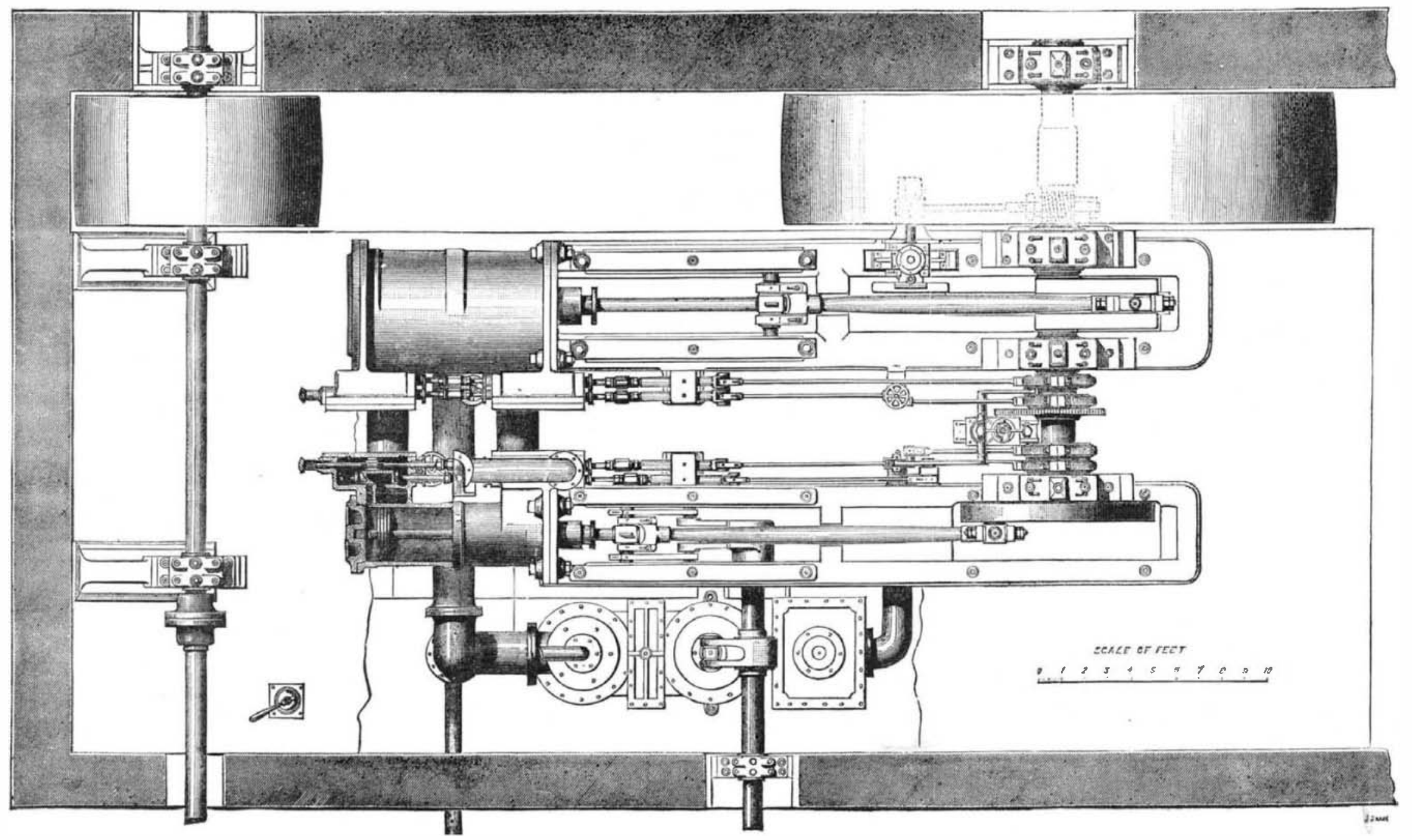

NEW 500 H. P. COMPOUND ENGINE 